\title{
Systemic health reforms may be a prelude to privatization, new CMA president says
}

Published at www.cmaj.ca on Aug. 26

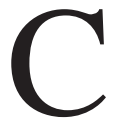

anada's doctors and patients have a collective responsibility to reform the delivery of health care so that they're getting the biggest bang for their buck, argued President Dr. Jeff Turnbull in his inaugural address at the Canadian Medical Association's annual general meeting in Niagara Falls, Ontario.

But Turnbull also indicated Wednesday during the CMA's wrap-up press conference that the association's erstwhile demands for the unleashing of more market-driven forces in Canadian health care are far from dead, but rather, merely deferred.

Privatization and/or the development of a parallel private health care system remain very much on the table, Turnbull said. "Canadians want us to define "what is a sustainable health care system that delivers value for money.' Canadians want us first to talk about issues of patient-centred care, including them in the decision-making process, quality and safety. They want to see access issues addressed and they want us to do that in a most efficient and effective way."

“Once we've defined that system, in a national dialogue with all partners, then that's going to allow us better to define exactly how we're going to have to support it. And then maybe, that discussion may require us to look at both private and public funding. That may require us to look at new models, through taxation support, etc. Who knows?"

In his earlier address to delegates, though, Turnbull cast sustainability as a function of equity, arguing that it should be defined within the parameters of "value for money" and ensuring that health care is equitably distributed among population groups, particularly "the vulnerable — the poor, the elderly, our First Nations, the disabled, the mentally ill and more."

"Sustainability isn't just about

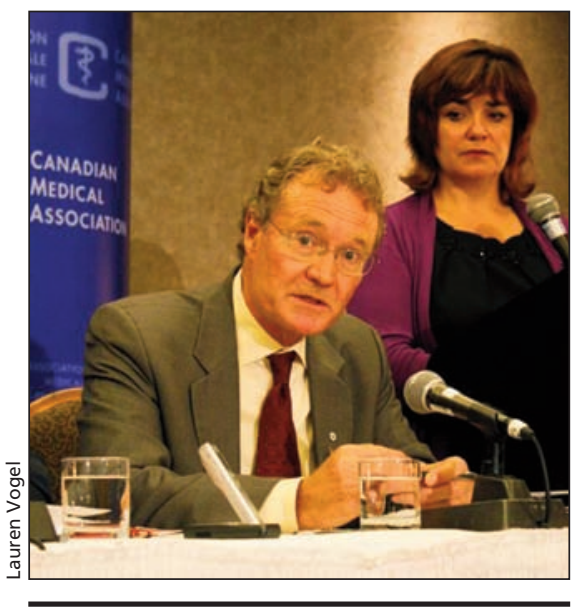

“Canadians want us first to talk about issues of patient-centred care, including them in the decision making process, quality and safety," says new CMA President Dr. Jeff Turnbull.

money," he told delegates. "It's about what that money gets us. It's about providing universal access to high quality health care, delivered in a cost-effective manner and with an emphasis on evidence and outcomes. There is no value in having financial sustainability if we don't use those resources to ensure and improve the overall quality of the system itself."

"We need to look at ways to allow patients to take more responsibility for their health and health care," Turnbull said, adding that what's needed, more than anything in Canadian health care, is "better and more effective systems of management and governance."

"Last year as a nation, we spent \$183 billion on our health care. And what did that get us? It got us ranked second-lowest among advanced countries in terms of value for money in health care."

"It's not a lack of resources. It's not an absence of will. It's a glaring failure of execution. Yes, there is a need for enhanced expenditures to allow for restructuring in areas such as information technology, electronic medial records, chronic care and pharmacare.
But more broadly, we can provide better and more effective health care by focusing on integrated care, a safety and quality agenda and evidence-based decision-making."

Notions of increased patient responsibility within the health care system are typically associated with demands for copayments or some form of user fees.

But when asked to define what he meant by patient responsibility, Turnbull cast the concept strictly within the parameters of patient-centred care.

'It's making all of the best information available to patients and allowing them to make meaningful decisions based on their priorities," he told reporters, later adding that "when patients become partners with you in the delivery of care, then they become more active participants."

Canadian Doctors for Medicare Vice-Chair Dr. Robert Woollard says Turnbull's concept of patient responsibility seems firmly rooted in health care equity, rather than some form of cost recovery from patients.

"He's very clearly talking about engaging patients. He's very clearly talking about how we, in our relationship with patients, can discuss the sustainability of the system and can ask, in a sense, hard questions, such as whether an MRI [magnetic resonance imaging] is necessary," says Woollard, a Vancouver, British Columbia, family physician and professor of family medicine at the University of British Columbia.

"He didn't shirk from the idea that there needs to be changes and that we need to improve but he cast that in the framework of the public health system," Woollard adds. "That was refreshing to see, instead of the standard whine and geez party we usually hear from doctors about how hard everything is for them." — Wayne Kondro, CMAJ

DOI:10.1503/cmaj.109-3355 